\title{
THE SISS IN THE NETHERLANDS: DESCRIPTIVES AND GENDER DIFFERENCES
}

\author{
Annita Alting and Willem J. Pelgrum \\ University of Twente, Department of Education, Enschede, The Netherlands
}

\section{Introduction}

The Netherlands participated in one part of the SISS, i.e. population 2, that is: students in the third grade (SISS grade 9) of lower secondary education. This population is of particular interest due to the diversity of school types and their associated science curricula and the fact that grade 9 still contains most of the students of an age cohort. The SISS offered a good opportunity to study the content of the science curriculum and student performance just before the transition to upper secondary grades takes place. Such an assessment is important as descriptive information in itself, because this information is not produced by other sources. In this article we first describe the structure of the Dutch school system in general and of lower secondary education in more detail. This description is combined with descriptive results from the SISS.

Besides the descriptive aspect the SISS data are of relevance for investigating a number of issues that are related to educational policy. One of these issues is the existence of large gender differences in the Netherlands with respect to the qualification of girls for particular kinds of jobs that traditionally belong to the realm of men. Many girls in secondary education choose for their final examination a selection of subjects that disqualifies them for a number of further studies, like medicine. mathematics, physics, chemistry and technology. This apparent tendency of girls not to take part in science courses in upper secondary education can 
possibly be traced back to, amongst others, their experience with and perceptions towards science in the period preceding upper secondary education. Therefore, it is interesting to use the SISS data in order to analyse the existence and possible causes of gender differences in achievement, attitudes and perceptions of science at this level of the educational system. These analyses might possibly throw some light on the origins of the subject selections made later on. Before presenting these analyses, we first discuss a theoretical approach to this problem by presenting a model that was proposed by Eccles et al. (1982) and Eccles (1987). Next, the results of the analyses are presented and discussed.

The Dutch School System and Some Descriptive Statistics from SISS

At the time of the data collection for the SISS, the Dutch school system had the following characteristics.

Kindergarten starts at age 4 . Students entered the school system at age 6. Elementary education comprised 6 grades. After elementary education students are streamed towards different types of schools in secondary education. Lower general secondary education consists of preuniversity school types (called Gymnasium, VWO), senior secondary education (HAVO)- and junior secondary education (MAVO).

MAVO qualifies for further education in HAVO or upper secondary vocational education. Junior vocational training consists of different school types, i.e. technical (LTO), administrative commercial (LEAO), domestic science (LHNO), nautical (LNO), and agricultural (LAO). Upper general secondary education comprises Gymnasium, VWO and HAVO, where students after grade 9 select certain courses for their final examination. which qualifies for entry to certain university studies or higher vocational education. Upper secondary vocational colleges education consists of different school types, i.e. technical (MTO), administrative/commercial (MEAO), social and nursery (MDGO) and a school type containing a mixture of vocational courses (KMBO).

The population of students for SISS was defined as "all students in the third grade of secondary education in the school types HAVO-VWO. MAVO, LTO, LHNO-LEAO and LAO". This population covers $95 \%$ of the total population of students and the fact that a small proportion of the population 
is excluded is assumed not to bias any national estimates of student achievement (Pelgrum \& Bruggencate, 1986).

Table 1: Sample sizes for schools, teachers and students

schooltype

Category SSE-PUE* JSE JTT JDT-JAdT JagT

\section{Population}

Schools

Students

$517 \quad 1125$

331

665

121

$\begin{array}{llll}76288 & 91975 & 43694 & 38418\end{array}$

7220

\section{SISS sample}

Schools

49

50

56

45

24

Teachers

\section{Biology}

Physics

Chemistry

Students

\section{3}

45

48

1209
42

35

2

44

24

52

2

19

43

4

23

$1232 \quad 1158$

938

528

\begin{abstract}
SSE: Senior Secondary Education; PUE: Pre-Universtiy
Education; JSE: Junior Secondary Education; JTT: Junior

Technical Training; JDT: Junior Domestic Science Training; JAdT:

Junior Administrative Training; JAgT: Junior Agricultural Training
\end{abstract}

The sample for SISS was stratified according to the categories of school types mentioned above and within each stratum a sample with probabilities proportional to size of schools was drawn. In each school one class of students (including the science teachers for that class) was selected randomly. Table 1 shows the sizes of the sample in terms of schools. teachers and students in each category of school types.

Table 2 shows some characteristics of this population broken down by school type as estimated from the SISS results.

Table 2 shows that the school types in general education and junior agricultural training are mixed with respect to gender, whereas junior 
technical training and junior domestic and administrative training are predominantly single-sex schools. It is also interesting to see that the socioeconomic background of parents differs between the school types.

Table 2: Characteristics of $9^{\text {th }}$ grade students as estimated from SISS

\section{School type}

Characteristics SSE-PUE*JSE JTT JDT-JAdT JAgT

Age (months)

Mean

183

185

$188 \quad 186$

186

Sd.

6.4

8.1

8.5

7.9

9.1

Gender (\%)

Boys

49

44

94

4

74

Girls

49

53

2

91

23

Father's education

after sec.education

none

1-2 years

3 and more

unknown

Language spoken at home

$\begin{array}{rrrrr}\% & & & & \\ 32 & 42 & 50 & 51 & 49 \\ 17 & 18 & 15 & 18 & 17 \\ 44 & 33 & 23 & 17 & 24 \\ 7 & 8 & 13 & 15 & 11 \\ \% & & & & \\ 68 & 56 & 46 & 33 & 34 \\ 21 & 32 & 44 & 51 & 57 \\ 8 & 9 & 5 & 11 & 4 \\ 3 & 3 & 5 & 5 & 5\end{array}$

Dutch

Dialect

Foreign

Unknown

.




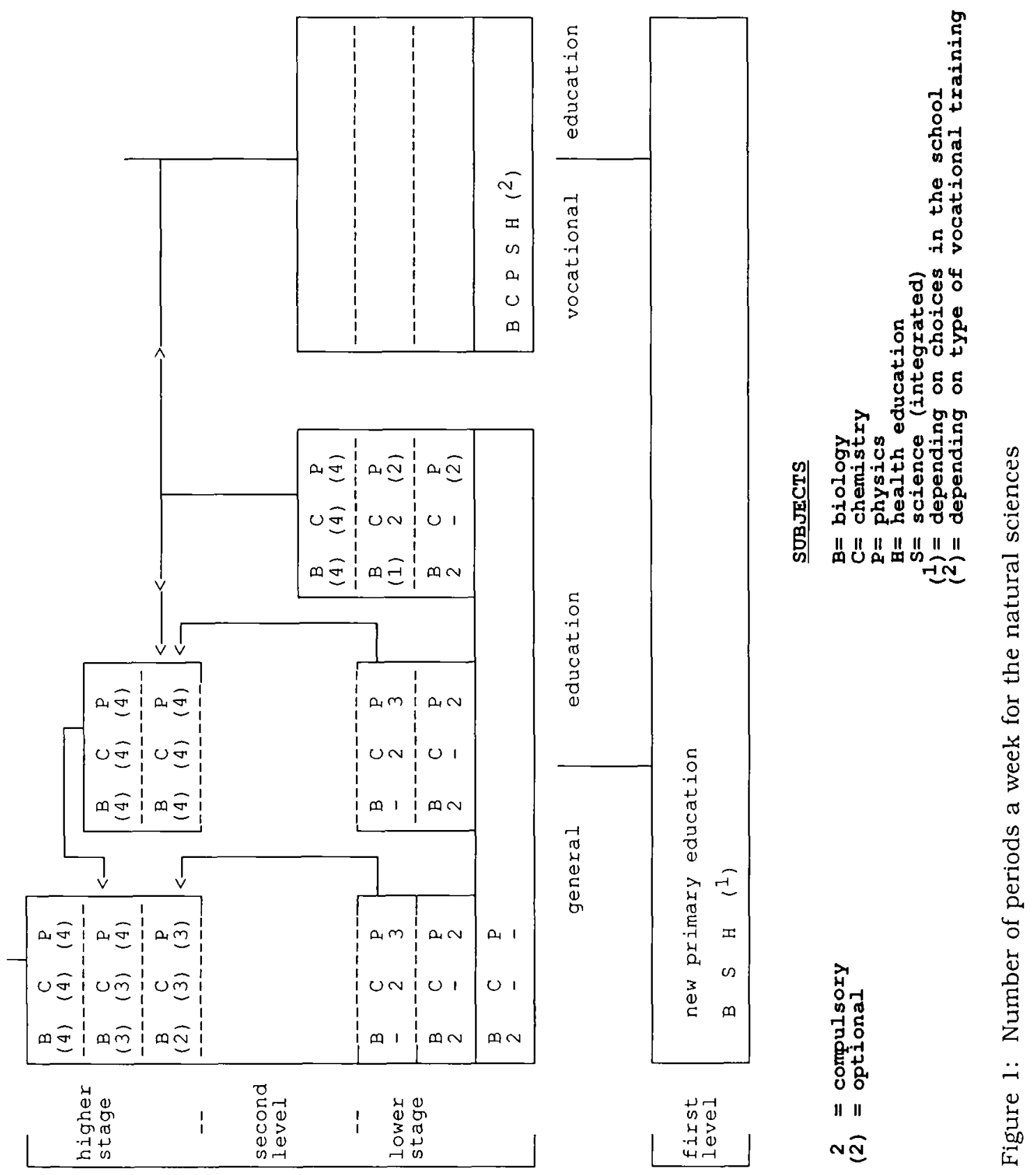


estimates of the amount of science subject matter covered in the different school types (Opportunity to Learn).

Table 3: Students attending classes in science and Opportunity to Learn (OTL) (in \% of students per schooltype)

\section{schooltype}

Variable

Classes in $(\%)$ :

Biology

Physics

Chemistry

OTL (\%)

Biology

Physics

Chemistry

*: Acronyms for schooltypes are explained in Table 1.

The achievement of students in science is one of the central variables in SISS. Figure 2 shows the distribution of total scores on the science tests for each of the different school types.

From Figure 2 it may be concluded that the achievement differences between the students in the differcnt school types are very large. These differences are not only associated with the general abilities of students (due to the selection procedures at the end of elementary education) but also with curricular offerings as was already shown in Table 3.

Gender-Differences in Science: A Theoretical Perspective

For decades large gender differences in choice of science subjects have been noted in many countries. Gender differences in performance alone cannot explain the large differences in subject choice (Kelly, 1981). 
The Netherlands does not form an exception to this situation. Table 4 shows the choice pattern at central final exams in schools for secondary general education.

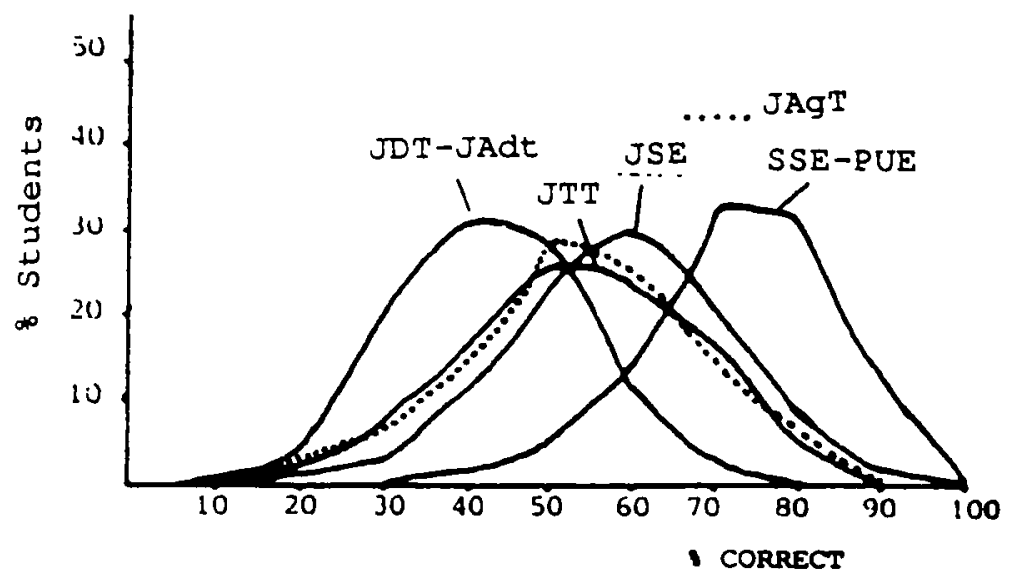

Figure 2: Distribution of percentages correct on the total science test

Table 4: Choice of science subjects in 3 types of general education; \% of male c.q. female candidates that took exams in a science subject in 1987

\section{schooltype}

\section{JSE*} SSE

PUE

subject boys girls boys girls boys girls

\begin{tabular}{lllllll} 
biology & 34 & 58 & 32 & 46 & 35 & 42 \\
chemistry & 54 & 35 & 42 & 28 & 52 & 32 \\
physics & 57 & 13 & 50 & 13 & 63 & 28 \\
\hline
\end{tabular}

* Acronyms for schooltypes are explained in Table 1. 
Physics, especially, is a prerequisite for entering many studies and trainings with good career prospects like senior technical training, technical college, and medical, science and technological studies at university. But since the early 70's, when the school types of Table 4 were established, the choice for physics stayed almost constant for girls but increased for boys. Physics has become even more of a "male subject" over the years!

The choice of biology (and to a lesser extent chemistry) shows a tendency to decline, both for girls and boys (Publications of the Central Bureau of Statistics, 1971-1988).

The large gender differences in subject choice are a point of major concern for educational policy-makers, science teachers and emancipationworkers in the educational field. For instance, since 1987 the Dutch Government has been running information campaigns using television, newspapers and brochures to enhance girls' choice for mathematics, science-subjects and technical training. Since the early 80's an influential working group of concerned science teachers has been installed in the Dutch Association for Science Education and, also at that time, several educational emancipation projects started, for instance the MENT-project that concerns itself with the position of girls in physics and technological education (MENT, in translation = Girls, Science and Technology) through carrying out research, developing materials and advising teachers.

A question of particular interest is what the educational and other experiences of girls are that lead to their choice (or non-choice) of schoolsubjects and what the relative importance of these experiences is. To avoid overlooking important variables that could influence subject choice, it is best to use a theoretical model that includes all possible variables that might predict subject choice, directly and indirectly. One such model,that is often used in Dutch research on gender differences in subject choice, is that developed by Eccles et al. (1982) and Eccles (1987) on the basis of an extensive literature study in the choice of mathematics. This model is presented in Figure 3.

The variables that directly influence subject choice in Eccles' models are:

Subjective Task Value, i.e. incentive value (interest in and liking of a subject), attainment value (the subject fulfills needs and personal values such as accentuation of one's self-image) and cost (relative amount of time and energy involved in studying a subject);

- Expectation of Success: expected success in coping with the subject. 


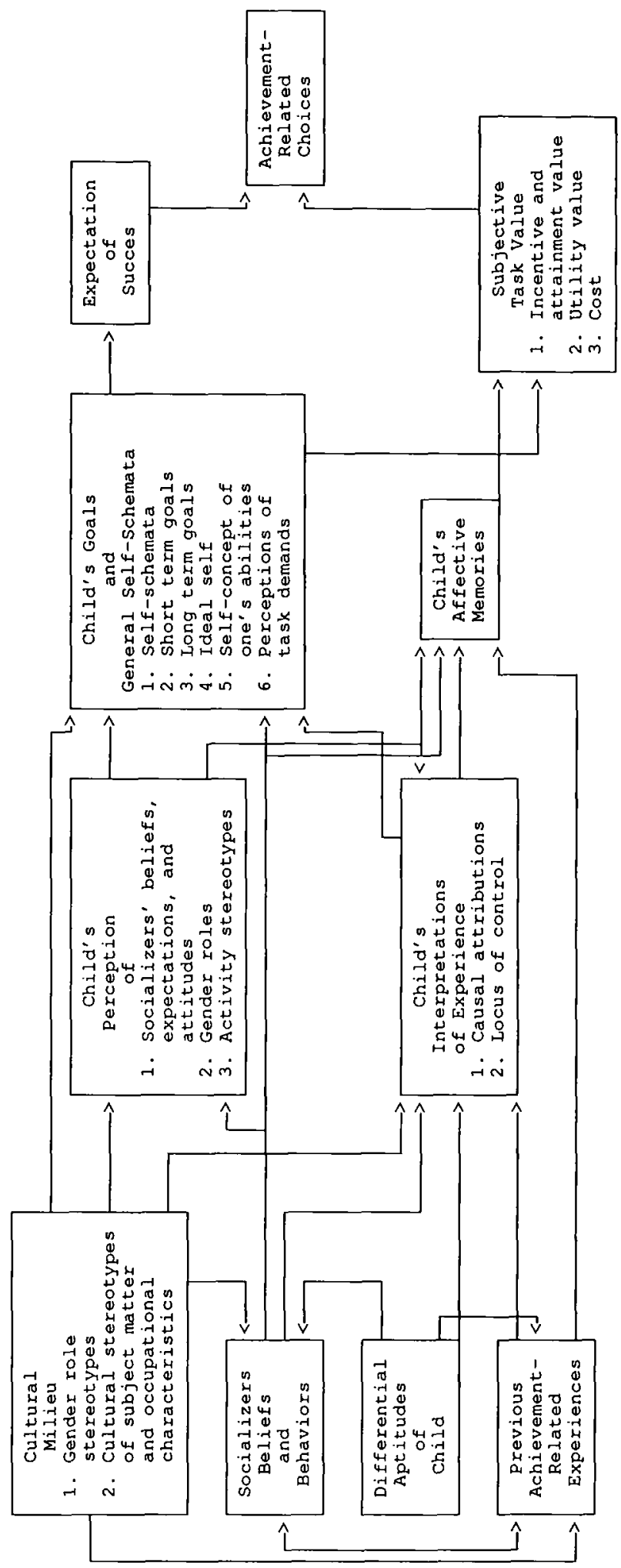

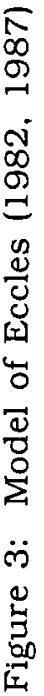


These variables are assumed to be influenced by many other variables, such as self-concept and goals, previous experiences, (perception of) socialisers' (such as teachers') beliefs and behaviours, etc. Ultimately all these variables are influenced by the cultural background. including gender stereotyping, and the differential aptitudes of a pupil.

We followed the model presented above for selecting variables from SISS and analysing the data in order to throw some light on the genderdifferences which exist in science interests and achievement and how these relate to subject choice. Before presenting the results of the analyses we shall first describe the variables selected from SISS.

\section{Selection of Variables from SISS}

Although the SISS does not cover all the variables that were identified by Eccles as potentially important sources for predicting subject choice. quite a number of matching variables could be found. Table 5 contains the variables that were selected for inclusion in the gender analyses.

Table 5: Selected variables from SISS

\begin{tabular}{ll} 
Variables & Description \\
\hline $\begin{array}{l}\text { Expectation } \\
\text { of success }\end{array}$ & Expected future education in science \\
$\begin{array}{l}\text { Perceptions of } \\
\text { task demands }\end{array}$ & Difficulty of science subject perceived \\
Goals & $\begin{array}{l}\text { Expected number of years in secondary } \\
\text { education }\end{array}$ \\
$\begin{array}{ll}\text { Subjective } \\
\text { task value }\end{array}$ & $\begin{array}{l}\text { Relevance for future and interest in } \\
\text { science subjects }\end{array}$ \\
$\begin{array}{l}\text { Perception of } \\
\text { socialisers' } \\
\text { behaviours }\end{array}$ & $\begin{array}{l}\text { Teachers' mentioning of relevance of } \\
\text { subject for future career and life; } \\
\text { teachers' making science subjects } \\
\text { interesting }\end{array}$ \\
\hline
\end{tabular}


From the SISS attitude instrument 6 scales could be constructed that relate as follows to Eccles' variables:

$\begin{array}{lll}\mathrm{REL} & \text { (Utility value: relevance for future life) } & 6 \text { items } \alpha=.62 \\ \mathrm{SOC} & \text { (Utility value: relevance for society) } & 6 \text { items } \alpha=.60 \\ \mathrm{CON} & \text { (Utility value: consequence of science) } & 4 \text { items } \alpha=.63 \\ \mathrm{INT} & \text { (Incentive value: interest in science) } & 4 \text { items } \alpha=.79 \\ \mathrm{DIF} & \begin{array}{l}\text { (Perception of task demands: } \\ \text { difficulty of science) }\end{array} & 4 \text { items } \alpha=.62 \\ \mathrm{SCH} & \text { (Incentive value: liking of school) } & 6 \text { items } \alpha=.78\end{array}$

Moreover, information was gained about the science achievements of girls and boys by asking them about their science achievement and by administering a SISS science test.

Achievement, like choice, is an outcome of the educational process that could best be included in "Achievement-Related Choices". The same can be said of the decisions pupils make on how much time to spend on their homework in science subjects, which also was a SISS-variable. This is in agreement with a more detailed description of the model, where Eccles distinguishes between 3 aspects of choice: choice of subject, performance and persistence on a task (Eccles et al., 1982).

\section{Groups Studied in SISS}

Due to the strong sex-segregation of junior vocational schools in the Netherlands -in itself a reason for concern-, it is not possible to make gender comparisons for these types of schools. Therefore we restrict the rest of this article to general secondary education, that is:

junior secondary schools; these contain about $36 \%$ of all students in the SISS population.

- senior secondary and pre-university schools together: these contain about $30 \%$ of the students in the SISS population.

In interpreting the results for these groups, we must be aware of the following complications:

- In junior secondary schools students can decide to drop physics and biology at the end of grade 2 . This leads to 2 data-sets for grade 3 : 
(1) Data about achievement, background variables and attitudes toward science apply to all students in grade 3 of junior secondary school. In comparing girls' and boys' attitudes, achievement and relevant background variables we must be aware that the majority of girls does not attend physics classes anymore. Moreover girls' and boys concept of science might be different because of differences in school background in science in grade 3 .

(2) Data about science subjects at school (homework, liking, grades) and teachers apply only to the students in grade 3 that still attend the science subjects. This means that girls are under-represented for physics and boys for biology.

- In junior secondary and pre-university schools all subjects are still obligatory in grade 3 . Only a few schools offer biology in grade 3 . This means that the data for biology at school students and for teachers level concern only a small group of students and may not be very representative.

Keeping this in mind we now turn to the research results. We shall indicate to what kind of groups the results refer as follows:

"all" : "all students in grade 3 of junior secondary education included";

"choosers" : "only the students that still attend physics and/or biology in grade 3 of junior secondary education".

Gender Differences and their Correlates from SISS.

First a description of differences between boys, and girls on the selected variables is provided, and next the correlates of these differences are discussed.

Goals

Table 6 shows that in comparison to boys, girls: expect to leave school earlier; are less inclined to attend future education, and expect less to attend further education that involves scientific subjects.

Science Achievement

Table 7 shows that, in comparison to boys, girls do not expect to perform better in science than in other subjects. 
Table 6: Expected future education ( $\%$ of boys and girls)

\section{schooltype**}

SSE-PUE JSE*

Future education

Expected last class at school

third

fourth

fifth bors girls

$1 \quad 1$

11

239

$\begin{array}{ll}69 & 37\end{array}$

\section{boys girls}

$\begin{array}{cc}5 & 3 \\ 72 & 81 \\ 15 & 12 \\ 5 & 3\end{array}$

Expected no. of years of

education after school

$\begin{array}{lcccc}\text { none } & 3 & 4 & 5 & 6 \\ 1-2 \text { years } & 10 & 15 & 20 & 23 \\ 3-4 \text { years } & 44 & 51 & 46 & 55 \\ >4 \text { years } & 42 & 29 & 28 & 16\end{array}$

Expects science in future

education

$55 \quad 34$

$48 \quad 41$

*: Acronyms for schooltypes are explained in Table 1.

: All sampled students

Table 7: Expectation of success in science subjects ( $\%$ of boys/girls)

Expectation

Expects to be better in

science subjects than in other subjects

$\frac{\text { schooltype** }}{\text { SSE-PUE JSE }}$

boys girls boys girls

$\begin{array}{llll}52 & 23 & 44 & 22\end{array}$

*: Acronyms for schooltypes are explained in Table 1.

**: All sampled students 
Attitudes

Table 8 contains the scores on the attitude scales for boys and girls as well as the standardized differences between the groups.

Table 8: Attitude scales: means and standardized differences d coding: $1=$ disagree, 2 = doubt/don't know, 3 = agree

\section{schooltype}

SSE-PUE $n=1182$

Scale boys girls

d sig

REL

2.3

2.1

$\mathrm{SOC}$

2.4

2.2

CON 2.3

2.3

INT

2.3

1.9

DIF 1.8

2.1

$\mathrm{SCH} \quad 2.0$

$\begin{array}{ll}.4 & * * * * \\ .5 & * * * * \\ -.05 & \text { n.s. } \\ .6 & * * * * \\ -.5 & * * * *\end{array}$

$-.2$ boys girls

d sig

JSE*

$\underline{n}=1195$

$\begin{array}{ll}2.2 & 2.1\end{array}$

$2.2 \quad 2.1$

$2.2 \quad 2.2$

$2.1 \quad 1.9$

$\begin{array}{ll}1.9 & 2.2\end{array}$

$1.9 \quad 2.0$

$\begin{array}{ll}.2 & * * * \\ .2 & * * * \\ -.04 & \mathrm{n} . \mathrm{s} \\ .3 & * * * \\ -.4 & * * * \\ -.2 & * * *\end{array}$

: Acronyms for schooltypes are explained in Table 1.

${ }^{* * *}$ sign at . $1 \%$ level ${ }^{* * * *}$ at $.01 \%$ level

$\mathrm{d}=$ (diff. between means) divided by standard deviation (s.d. practically equal for boys and girls)

REL - Relevance for future life

SOC - Relevance for society

CON - Consequences of science

INT - Interest in science

DIF - Difficulty of science

$\mathrm{SCH}$ - Liking school

Table 8 shows that girls in comparison to boys tend to perceive science as difficult and not to like it.

It is interesting to see that girls tend to generally like school more than do boys and that there are no differences with respect to the perceived consequences (CON) of science. Thus, it seems that although girls are positive about school in general and about science in society. they 
are less inclined to perceive science as useful for themselves and as an interesting school subject.

The gender differences presented in Tables 6 to 8 refer to "science in general" with no distinction between biology, physics and chemistry. It is known however, that girls like life-sciences (biology) much more than physics and chemistry and this is reflected in their choices (see also Table 4. "Choice of science subjects"). Also, in Dutch general education no such thing as "general" or "integrated" science is offered, but always the three distinct subjects of biology, chemistry and physics. For these reasons it is important to analyse the SISS-data for distinct school subjects with respect to gender differences.

Achievement

Table 9 shows the means and standardized differences for recent grades (measured on a scale from $0=$ lowest to $10=$ highest) and SISS scores. Except for recent school grades in biology all differences are statistically significant $(\mathrm{P} \leq .01)$. For physics and chemistry the differences are significant -even for physics in junior secondary schools where only choosers of the subject are included.

The SISS-achievement results concern all students in grade 3 , also the ones in junior secondary schools who have not chosen physics and/or biology. For senior secondary and pre-university education and chemistry in junior secondary education we may compare standardized differences on SISS with standardized differences on recent school grades. We see that the gender differences on SISS tests are larger than on recent grades, especially for physics. Causes might be sought in:

- nature of the test: multiple choice v.s. the open-ended questions mostly used in school practice. It is hypothesized that multiple choice tests favour boys (Harding, 1979)

- context of the experience: more in agreement with boys' experience and interests than with girls'

- opportunity to learn outside the school: boys have more physicsrelated out-of-school experience than girls, and the SISS tests contain items for which the Opportunity to Learn (OTL) at school was low, whereas school tests always concern subject matter previously treated in class. Boys could have profited from their out-of-school experience in doing SISS items for which OTL at school was low. 
Table 9: Gender-differences in achievement in recent school grades and on SISS-tests (means and standardized differences)

SSE-PUE

Achievement boys girls $d$
JSE*

\section{boys gir1s d}

Recent grades:

$\begin{array}{lllllll}\text { biology } & 7.2 & 6.9 & .2 & 6.8^{* *} & 6.7 & .1 \\ \text { physics } & 6.9 & 6.4 & .4 & 6.9^{* *} & 6.5 & .3 \\ \text { chemistry } & 7.0 & 6.7 & .3 & 6.9^{* *} & 6.5 & .3\end{array}$

SISS-tests:

\begin{tabular}{lllllll} 
biology & 70 & 65 & .4 & 60 & 55 & .3 \\
physics & 81 & 72 & .7 & 67 & 55 & .8 \\
chemistry & 78 & 73 & .3 & 59 & 50 & .5 \\
\hline
\end{tabular}

*: Acronyms for schooltypes are explained in Table 1.

** Only for choosers

Perseverance (Time Spent on Homework) and Liking of Science Subjects.

In Table 10 the results are presented on homework and liking of a particular subject as compared to other subjects. Girls seem to spend as much or a little more time on physics and chemistry than do boys, but they spend significantly more time on biology. Biology is most often mentioned as favourite subject by girls, and physics by boys in senior secondary and pre-university education. In junior secondary education the group consists of choosers of biology and/or physics. In this group gender differences are smaller, as could be expected. Still, physics seems to be relatively unpopular amongst the larger part of girl-choosers, which gives cause for concern because after the third grade there is another opportunity to drop subjects for final exams. 
Table 10: Time spent on homework (minutes) and liking of subjects compared to other subjects ( $1=$ like better, $2=$ as much as, $3=$ like less)

\section{Schooltype}

SSE-PUE JSE $^{*}$

Time/ boys girls $n$ boys**girls** $n$

Liking

Time

spent on

homework:

$\begin{array}{lcccccc}\text { biology } & 42 & 69 & 108 & 72 & 89 & 995 \\ \text { physics } & 84 & 88 & 1140 & 80 & 80 & 700 \\ \text { chemistry } & 76 & 83 & 1120 & 78 & 78 & 1079\end{array}$

Liking of

subject:

$\begin{array}{lllllll}\text { biology } & 2.2 & 1.6 & 129 & 1.9 & 1.7 & 1014\end{array}$

$\begin{array}{lllllll}\text { physics } & 1.8 & 2.4 & 1153 & 1.9 & 2.3 & 717\end{array}$

$\begin{array}{lllllll}\text { chemistry } & 1.9 & 2.2 & 1153 & 2.0 & 2.3 & 1108\end{array}$

*: Acronyms for schooltypes are explained in Table 1.

** : Choosers

\section{Intercorrelations}

In Table 11 the Pearson correlation coefficients are shown for achievement on SISS-tests, attitude scales, gender, future education and success expectation in science for grade 3 . The correlation matrix gives no more than a global impression of possible relations, since no distinction is made between school-types, gender, choosers and non-choosers of biology and physics. We see that the expectation of attending future education in science correlates most strongly with interest in science $(r=.53)$, perceived relevance for the future $(r=.32)$ and success expectation $(r=$ .35) which is in agreement with Eccles' model. Liking school, perceived 
consequences of science and gender have the weakest direct correlations with expecting a future education in science $(r=.07, .09,-.12$ respectively).

Table 11: Pearson correlation coefficients: achievement, attitudes, expectations and gender for "science"

\begin{tabular}{|c|c|c|c|c|c|c|c|c|c|c|}
\hline $\begin{array}{l}1 \\
\text { SISS } \\
\text { test } \\
\text { bio }\end{array}$ & $\begin{array}{l}2 \\
\text { SISS } \\
\text { test } \\
\text { chem }\end{array}$ & $\begin{array}{l}3 \\
\text { SISS } \\
\text { test } \\
\text { iphys }\end{array}$ & $\begin{array}{l}4 \\
\mathrm{REL}\end{array}$ & $\begin{array}{l}5 \\
\text { SOC }\end{array}$ & $\begin{array}{l}6 \\
\text { INT }\end{array}$ & $\begin{array}{l}7 \\
\mathrm{CON}\end{array}$ & $\begin{array}{l}8 \\
\mathrm{SCH}\end{array}$ & $\begin{array}{l}9 \\
\text { SEX }\end{array}$ & $\begin{array}{l}10 \\
\text { Sci- } \\
\text { ence } \\
\text { fur- } \\
\text { ther }\end{array}$ & $\begin{array}{ll}\text { l } 1 & 12 \\
\text { High } & \text { Good } \\
\text { class } & \text { in } \\
& \text { science }\end{array}$ \\
\hline
\end{tabular}

\begin{tabular}{lllllllllllll}
\hline 1 & 1.0 & .57 & .55 & .22 & .24 & .28 & .10 & .08 & -.17 & .18 & .30 & .19 \\
2 & & 1.0 & .64 & .23 & .22 & .31 & .11 & .08 & -.33 & .22 & .42 & .23 \\
3 & & & 1.0 & .22 & .24 & .28 & .12 & .11 & -.18 & .18 & .46 & .18 \\
4 & & & & 1.0 & .41 & .44 & -.0 & .11 & -.16 & .32 & .16 & .25 \\
5 & & & & & 1.0 & .39 & .21 & .16 & -.19 & .23 & .16 & .22 \\
6 & & & & & & 1.0 & .15 & .20 & -.21 & .53 & .14 & .47 \\
7 & & & & & & & 1.0 & .19 & .02 & .09 & .13 & .07 \\
8 & & & & & & & & 1.0 & .10 & .07 & .18 &.- .0 \\
9 & & & & & & & & & 1.0 & -.12 & -.07 & -.26 \\
10 & & & & & & & & & & 1.0 & -.09 & .35 \\
11 & & & & & & & & & & & 1.0 & .06 \\
12 & & & & & & & & & & & & 1.0 \\
\hline
\end{tabular}

Since there are many high intercorrelations between variables, more sophisticated analyses will be needed and distinctions will also have to be made between school types and choosers and non-choosers in junior secondary education, to get a clearer picture.

\section{Teacher Behaviour}

To conclude our inventory of gender differences we show the results for some behaviours of teachers as perceived by boys and girls in Table 12 . 
Table 12: Perceived teacher behaviour $(1=$ often perceived, $2=$ sometimes, 3 = never)

schooltype

\section{$\underline{\text { SSE-PUE }} \quad \underline{\text { JSE* }}$}

Teacher boys girls $n$ boys girls $n$

Behaviour

Teacher makes

lessons

interesting

Biology

$\begin{array}{lll}2.2 & 2.0 & 46\end{array}$

$\begin{array}{lll}1.9 & 1.8 & 350\end{array}$

Physics

$\begin{array}{lll}1.8 & 2.1 & 440\end{array}$

$\begin{array}{lll}1.8 & 2.0 & 239\end{array}$

Chemistry

$\begin{array}{lll}1.9 & 2.0 \quad 415\end{array}$

$\begin{array}{lll}1.9 & 2.1 & 400\end{array}$

Teacher ex-

plains impor-

tance for per-

sonal life

Biology

$\begin{array}{lll}2.6 & 2.3 & 46\end{array}$

$\begin{array}{lll}2.4 & 2.2 & 349\end{array}$

Physics

$\begin{array}{lll}2.5 & 2.6 & 439\end{array}$

$\begin{array}{lll}2.4 & 2.4 & 237\end{array}$

Chemistry

$\begin{array}{lll}2.9 & 2.5 & 412\end{array}$

$\begin{array}{lll}2.4 & 2.4 & 400\end{array}$

Teacher talks

about possible

biological

etc. jobs

Biology

$\begin{array}{lll}2.9 & 2.5 & 46\end{array}$

$\begin{array}{lll}2.6 & 2.6 & 348\end{array}$

Physics

$\begin{array}{lll}2.7 & 2.8 & 441\end{array}$

$\begin{array}{lll}2.6 & 2.6 & 239\end{array}$

Chemistry

$\begin{array}{lll}2.8 & 2.9 & 413\end{array}$

$\begin{array}{lll}2.6 & 2.7 & 402\end{array}$

: Acronyms for schooltypes are explained in Table 1. 
For chemistry and physics girls less than boys are of the opinion that the teacher makes the lessons interesting for them. For biology the opposite is the case. For the other behaviours it is most striking that students observe them so seldomly, especially in senior secondary and preuniversity education.

For both school types and all three subjects the correlation matrices show the same pattern except for biology in senior secondary and preuniversity education:

Liking of the subject correlates most strongly with good grades and teachers making the lessons interesting $(.37<\mathrm{r}<.48)$, and most weakly with time spent on homework $(.02<\mathrm{r}<.11)$. About the influence of teachers' mentioning the importance of the subject for daily life and jobs nothing can be said because of the nature of the distribution of the data.

The data for senior secondary and pre-university biology refer to only 46 students ( 2 classes) and are not representative. For this small group of students liking biology correlates most strongly with all three teacher variables and very weakly with biology grades and time spent on homework.

\section{Conclusions}

Eccles model proved useful in the analysis of gender differences in SISS. Most SISS variables can be included in the model and the model also shows variables not in SISS that can be important in subject choice processes. The results we found until now invite further exploration using Eccles' model, especially concerning the question "What makes science subjects interesting for girls and boys and what can the teacher do about this?" Systematic research in this area is scarce, though there are indications that physics teachers unconsciously cater to the interest and experiences of boys when they want to make their subject interesting for "students" (de Leeuw 1986). Also, a more detailed analysis of SISS test items is necessary to understand better why girls' under achievement in physics and biology is so much more pronounced than on school-made tests. Some suggestions about possible causes have been given in this paper. but they have not yet been investigated thoroughly. 
References

De Leeuw, A, Raat, J.H. (1986). Interest of girls and new teaching material. In: M. Dahms et al., (Eds). Women challenge technology. Contributions to the European Conference on Women, Natural Sciences and Technology. University of Aalborg, Denmark.

Eccles Parsons, J.S, Kaczala, C.M, Geoff, S.B, \& Futterman, R. (1982). Sex differences in math achievement: Toward a model of academic choice. Psychological Bulletin, Vol 91, No. 2, 324-348.

Eccles, J.S. (1987). Gender roles and women's achievement-related decisions. Psychology of Women Quarterly, 11, 135-172.

Harding J., (1979, July) Sex differences in examination performance at $16+$ Physics Education, 14, 5.

Kelly. A., (Ed.) (1981). The missing half; girls and science education. Manchester: Manchester University Press.

Pelgrum, W.J. \& Bruggencate, G.C. (1986a). Second International Science Study: Technical Report. Enschede, The Netherlands: T.H. - Twente, Toegepaste Onderwijskunde.

Pelgrum, W.J. \& Plomp, T. (1986b). De "Second International Science Study": Beschryving en Analyses. Enschede. The Netherlands: T.H. Twente, Toegepaste Onderwijskunde.

\section{The Authors}

ANNITA ALTING studied physics at Groningen University and worked as a teacher in physics and mathematics in secondary education and higher technical education. Since 1984 she does research and develops workshops for teachers in the MENT-project (Girls, Physics and Technology) at Eindhoven University of Technology. She has been involved in research in the INV-project (Inventarisation of Science Subjects) at Twente University of Technology and Social Sciences. Annita Alting is a member of the Dutch ASE Working Group "Women and Science".

W.J. PELGRUM has a Ph.D. from the University of Twente and is a Senior Researcher at its Department of Education. His research concerns vocational education, and he has been National Research Coordinator in the IEA Second Mathematics Study as well as International Coordinator of IEA Computers in Education Study. 